\title{
Crop Yield Sensitivity to Climatic Variability as the Basis for Creating Climate Resilient Agriculture
}

\author{
David Chikodzi \\ Department of Physics, Geography and Environmental Science, Great Zimbabwe University, Masvingo, \\ Zimbabwe \\ Email: dchikodzi@hotmail.com
}

Received 16 September 2015; accepted 27 March 2016; published 30 March 2016

Copyright (C) 2016 by author and Scientific Research Publishing Inc.

This work is licensed under the Creative Commons Attribution International License (CC BY). http://creativecommons.org/licenses/by/4.0/

(c) (i) Open Access

\begin{abstract}
Climate change and variability are presenting challenges to the agricultural sector as well as agricultural sustainability in Zimbabwe. This paper was aimed at investigating the impacts of climate change and variability on maize, sorghum and groundnut production in the Buhera district of Zimbabwe. The paper specifically determined the climatic scenarios in Buhera and how crop production is sensitive to them. Temperature and rainfall data used were obtained from the Zimbabwe Meteorological Services Department. Crop yield data for maize, sorghum and groundnuts were obtained from the Department of Agriculture and Rural Extension Buhera District office. The Mann-Kendall Trend test was then used to determine if there were significant changes in the precipitation and temperature scenarios at Buhera weather station. Before performing the MannKendall test, the time series data were first tested for auto-correlation. Finally the Spearman's correlation coefficient was used to determine how precipitation and crop yields were related and the strength of their relationships. Mann-Kendall trend tests reviewed that only mean minimum temperatures show significant trends over time $(p=0.003, \alpha=0.05)$. Correlation analysis showed that only maize showed a significant correlation coefficient with the amount of rainfall $\left(r=0.79, r^{2}=\right.$ 0.625 and $p=0.001, \alpha=0.05$ ). The research showed that groundnuts were the least sensitive to climatic variations followed by sorghum; hence their production offers the best climatic resilience and must be encouraged to local subsistence farmers.
\end{abstract}

\section{Keywords}

Climate Change, Crop Yield Sensitivity, Climate Resilience, Buhera District 


\section{Introduction}

In Africa, climate change and variability are causing serious decline in crop production in most countries. It has been determined to be the major cause of severe droughts and weather conditions in these countries. Most African countries have improved their agricultural technology in the past century but extreme weather events induced by climate change have caused significant yield reductions in some years [1]. Climate change is now viewed as a major threat to societies and their economic development. It presents risks to lives and livelihoods at the individual level and to the economy and infrastructure at the regional and national levels [2].

Rain fed smallholder agriculture is the backbone of rural household livelihoods and national economies in the most countries of southern African, contributing over $90 \%$ of direct and indirect employment in the region. Climate change and variability have late presented challenges to the agricultural sector as well as agricultural sustainability in these countries [3]. In Zimbabwe, rainfall now exhibits considerable spatial and temporal variability characterised by shifts of onset of rains, increase in the frequency and intensity of heavy rainfall events, increase in the proportion of low rainfall years, decrease in low intensity rainfall events and increase in the frequency and intensity of mid-season dry spells [4].

The Intergovernmental Panel on Climate Change (IPCC) defines vulnerability as a combination of a system's exposure to threats, its sensitivity and capacity to adapt to such threats [5]. More effective agricultural systems and practices are therefore urgently needed to help especially the poor and vulnerable smallholder farmers to maintain, increase, and improve their agricultural production despite climate change. Determining sensitivity of crop production to climate change and variability is crucial to Zimbabwe's communal farmers because it is a step towards informed selection of the most suitable crops that offer guaranteed yields, hence building climate resilient agriculture [6].

In the last 30 years the climate of Southern Africa has shown various changes, especially in terms of rainfall, of which inter-annual variability is very high. This has significant consequences for the poor resourced communal farmers, whose incomes, nutrition and livelihoods depend mainly on rain fed agriculture. With about two thirds of Zimbabwe comprising arid and semi-arid lands, adaptation and mitigation strategies to climate change are a priority since the majority in these areas are vulnerable yet dependent on rain fed agriculture. This paper investigates the impact of climate change and variability on maize, sorghum and groundnut production in the Buhera district of Zimbabwe. Specifically the paper determines how climate change and variability occur and how crop production has responded using a panel dataset.

\section{Methods and Materials}

\subsection{Study Area}

Figure 1 shows the location of Buhera district. It lies at latitude $-19.5^{\circ} \mathrm{S}$, longitude of $32^{\circ} \mathrm{E}$ and it has an average

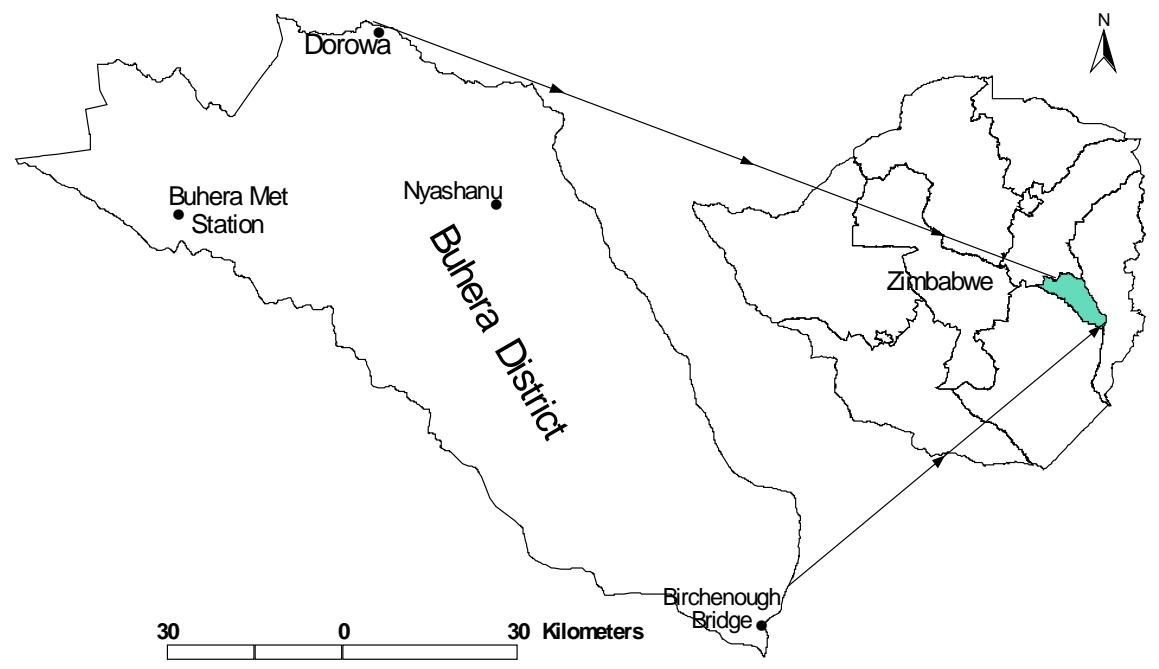

Figure 1. Study area—Buhera district of Zimbabwe. 
elevation of 864 meters above sea level. The district has a total surface area of $5357.27 \mathrm{~km}^{2}$ and a population of 246,462 of which 114,231 are males and 132,231 are females making a population density of 45.9 people $/ \mathrm{km}^{2}$ [7]. The district is located in Manicaland Province, south eastern Zimbabwe and is predominantly rural, 100\% communal. Most people in the area are communal farmers who grow mainly maize, groundnuts, sorghum and rapoko. Maize is the most important crop in the area, has a dual role in the economy of Buhera and the general well-being of the populace. The crop serves as both a cash crop as well as being used as a staple diet for the majority of the people in the district and country at large [8]-[10].

\subsection{Methods}

Temperature and rainfall data used in the study were obtained from the Zimbabwe Meteorological Services Department. Data from the Buhera weather station were used because it is the only station run by the Meteorological Services Department in the district. Crop yield data were obtained from the Department of Agriculture and Rural Extension (AREX) Buhera District office.

Before performing statistical data analysis, all the data was first tested for their distribution and for serial correlation. The distribution test to determine if data was normally distributed or random was performed using the Kolmogorov-Smirnov test in SPSS software. This information was required to determine whether parametric and non-parametric tests could be used in data analysis.

Autocorrelation refers to the correlation of a time series with its own past and future values. It complicates the application of statistical tests by reducing the number of independent observations and increases the chances of detecting significant trends even if they are absent and vice versa [11]. Before performing the Mann-Kendall test, the time series data of temperature and precipitation were first tested for auto-correlation in a statistical package Paleontological Statistics (PAST) Version 3.0. If serial correlation is detected, the data would then be pre-whitened in PAST 3.0 using the ARIMA model. The model reduces residuals in the time series to white noise which then removes the possibility of finding significant trends in the Mann-Kendall test when actually there are no trends [12].

Mann-Kendall Trend test was then used to determine if there were significant changes in the precipitation and temperature scenarios with time at Buhera weather station. The Mann-Kendall test is a non-parametric test for the detection of trends in time series. The test was used because it is simple, robust, can cope with missing values, seasonality and values below detection limit [13] [14]. The Mann-Kendall tests were performed using the Addinsoft's XLSTAT 2013 software. The null hypothesis which states that there is no significant trend, is tested at $95 \%$ confidence level for both temperature and precipitation data.

Finally correlation analysis was done in order to determine how the two variables in question (precipitation and crop yields) were related and the strength of their relationships. The Spearman's correlation coefficient (rho) was used because it is more robust when used to analyse non parametric data and also because the data is monotonic. It assesses how well the relationship between two variables can be described using a monotonic function and the correlations were tested for statistical significance $(p=0.05)$ in order to assess whether observations reflected a true pattern or just occurred by chance.

\section{Results}

Normality tests done on precipitation and temperature data using the Kolmogorov-Smirnov test shows that data were randomly distributed ( $\mathrm{p}=0.001$ and $\alpha=0.05$ ). Tests for serial correlations in all the time series data reviewed that the data was not auto-correlated hence no special need for pre-whitening before performing the Mann-Kendall tests. The mean maximum temperature at Buhera weather station from 1961-2000 is shown in Figure 2. It is highly variable from year to year but in general display an increasing trend. The decade from 1961-1971 shows that maximum temperatures slightly increased with many pick temperatures going above $35^{\circ} \mathrm{C}$. The next decade from 1971-1982 had subdued maximum temperature and the coolest in the time series of the station. From 1983-2000 maximum temperatures were again on the increase. In comparison with a nearby weather station Chisumbanje, the rate at which mean maximum temperatures are increasing at Buhera station are noted to be lower than the former which has a steeper gradient of the trend line ( $\mathrm{X}$ coefficient of 0.0102 as compared to X coefficient of 0.0018 at Buhera)

Figure 3 shows the scenarios of average minimum temperatures at Buhera weather station from 1961-2000. The figure shows that minimum temperatures have high variability of up to $10^{\circ} \mathrm{C}$ from year to year have. The 


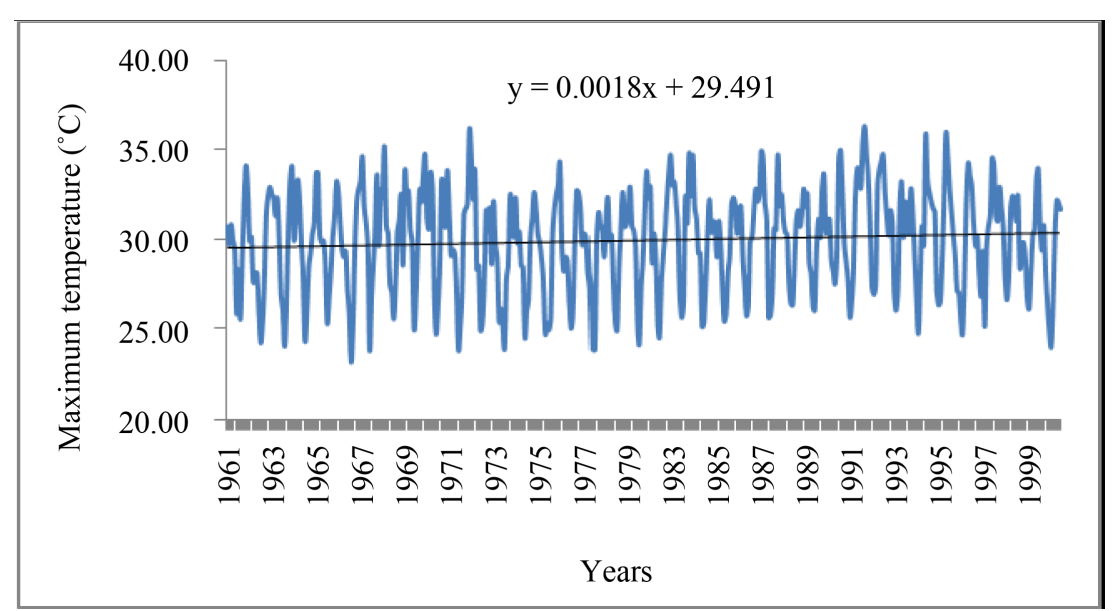

Figure 2. Mean maximum temperatures at Buhera weather station from 1961-2000.

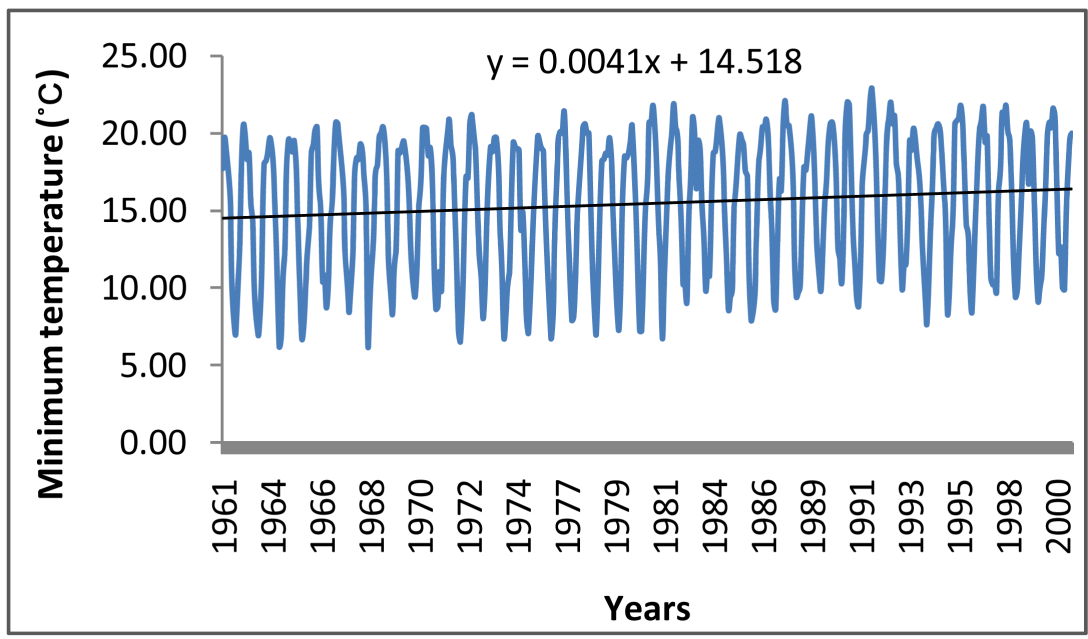

Figure 3. Mean minimum temperatures at Buhera weather station from 1961-2000.

minimum temperatures show an increasing trend from an average of less than $15^{\circ} \mathrm{C}$ in 1961 to over $16^{\circ} \mathrm{C}$ in the year 2000. The two decades from 1961 to 1981 were the coolest in Buhera in terms of minimum temperature and characterised by relatively declining mean minimum temperatures. From 1982-2000 the minimum temperatures began to rise with the period 1982-1993 having the steepest increase. The nearby Chisumbanje weather station in comparison has got a steeper rate at which mean minimum temperatures are increasing ( $\mathrm{X}$ coefficient of 0.0214). Hence the rate at which Buhera winter temperatures are warming is lower when compared to nearby regions.

Figure 4 shows the trends of mean annual rainfall at Buhera station from 1951-2011. The figure shows that there is high inter-annual variability in rainfall over the station. The rainfall pattern also exhibits a 10 year cyclic pattern in peak low rainfall totals as noted in the 1953, 1963, 1982 and 2000 seasons. The time series shows that on average there are more years of below normal rainfall than above normal. In terms of decadal variability in rainfall totals, the time period between 1961-1975 had the least decline in rainfall with a gradient coefficient of $\mathrm{x}$ being -1.7. The two decades from 1975-1995 saw the steepest decline in average rainfall as indicated by an X coefficient of -24 on the trendline equation of the two decades' timeseries. Between 1995-2000 the decline in rainfall had slowed to a gradient $X$ coefficient of -7 . In comparison with nearby weather stations Bikita and Chisumbanje all to the south of Buhera, Bikita is also showing a declining trend in rainfall patterns but its rate of decline is lower than that observed in the study area. Chisumbanje has however shown a slight increase in rainfall totals hence Buhera has much more reduced rainfall amounts compared to the surrounding regions.

Therefore in Buhera both minimum and maximum temperatures have been noted to be on the rise while as 


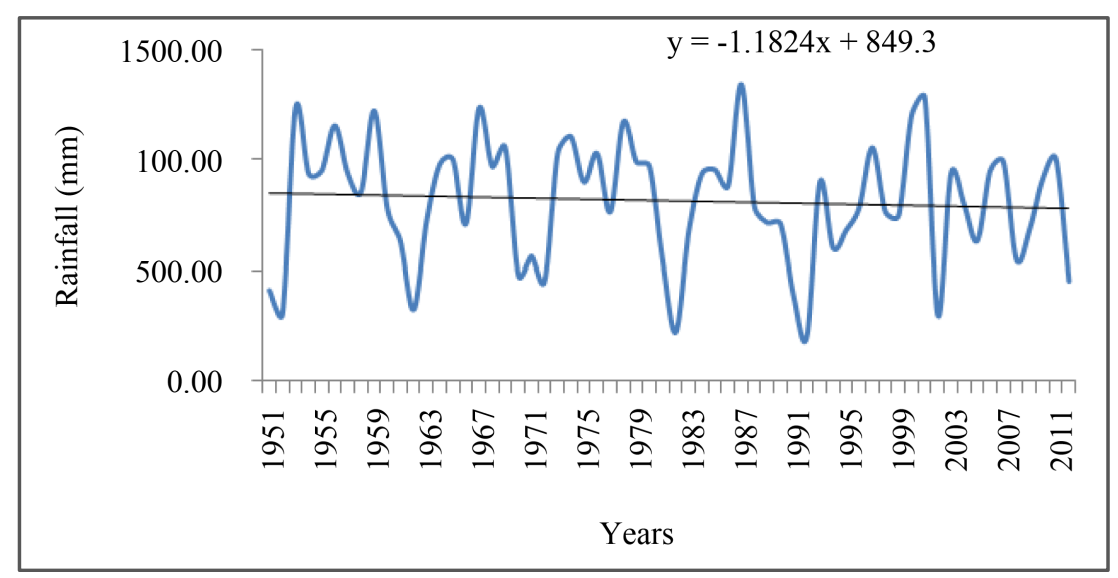

Figure 4. Mean annual rainfall at Buhera station from 1951-2011.

average rainfall amounts have been shown to be declining. To determine if the observed trends were statistically significant or occurring by random chance, Mann-Kendall trend tests were run (Table 1). Table 1 shows the results of the Mann-Kendall trend tests run on temperature and rainfall data from Buhera station. Only mean minimum temperatures show significant increase over time. This means that in Buhera, night and winter temperatures are now significantly warmer today than in the past. The same trend has been observed nearby at both Chisumbanje and Bikita stations. The trends observed on increasing maximum temperatures and rainfall decline do not yet show any statistical significance which means that the shifts are still within the natural cycle of variability.

Figure 5 shows the relations between yields of three staple crops: maize, sorghum and groundnuts to rainfall totals grown in Buhera district. Figure 5 shows that there are positive correlations between all crop yields and rainfall totals as any increase in rainfall amounts are always met by a corresponding increase in crop yields. However maize is most sensitive to changes in rainfall as any slight decline in rain is met by a big drop in maize yields as noted especially during the 2002 season. The same pattern of rainfall-crop yields relationship has been noted in neighbouring districts of Gutu, Chipinge and Bikita were maize is the most sensitive and groundnuts the least sensitive crop to changes in rainfall amounts.

Table 2 shows the coefficient of determination $\left(r^{2}\right)$, spearman correlation coefficient ( $r$ ) and p-values of the relationships between maize, sorghum, groundnuts and rainfall totals in Buhera District. Only maize shows a significant correlation coefficient with the amount of rainfall using both $\mathrm{r}^{2}$ and the $\mathrm{p}$-value. This means that the decline in rainfall amounts have had very serious consequences for maize production in Buhera District and has implications on food security since maize is the main staple food for the area. With a coefficient of determination of 0.625 , prediction of maize yield using rainfall amounts can be statistically done for yield forecasting and planning in Buhera District.

\section{Discussion}

The study revealed that Buhera is experiencing frequent crop failure due to mainly climate change and climate variability and also because of the farmers decision to dedicate most of their productive land to maize production which is significantly sensitive to climatic fluctuations especially precipitation. Specifically crop yields in Buhera have been affected by significant increases in temperatures in a cycle of highly variable precipitation that is in a state of long term decline. Globally growing evidence has been noted that increases in global temperatures are leading to changes in the amount of rainfall which significantly affect crop production [15] [16].

The results showing that mean minimum temperatures to have significantly increased means that crops are now exposed for longer hours to evapo-transpiration and become susceptible to moisture stress especially during the dry spell periods of the rainfall season. The dry spells of this region have been shown to have increased in both frequency and length, [17], hence the choice of crop planted by farmers becomes important.

Increases in temperatures have been proven to be capable of increasing evapo-transporative demand which in turn increases the rate of water loss the soil [18]. Small changes in actual evapo-transpiration can lead to huge 
Table 1. Mann-Kendall trend test results for mean minimum and maximum temperatures and rainfall at Buhera station.

\begin{tabular}{cccc}
\hline Climatic Parameter & P-Value & $\mathbf{H}_{\mathbf{0}}$ Decision & Trend Description \\
\hline Mean maximum temperature & 0.097 & Retained & Increasing but not significant \\
Mean minimum temperature & 0.003 & Rejected & Significantly increasing \\
Mean annual rainfall & 0.250 & Retained & Declining but not significant \\
\hline
\end{tabular}

Table 2. Coefficient of determination, Spearman correlation coefficient and P-values of the relationships between maize, sorghum, groundnuts and rainfall totals in Buhera district.

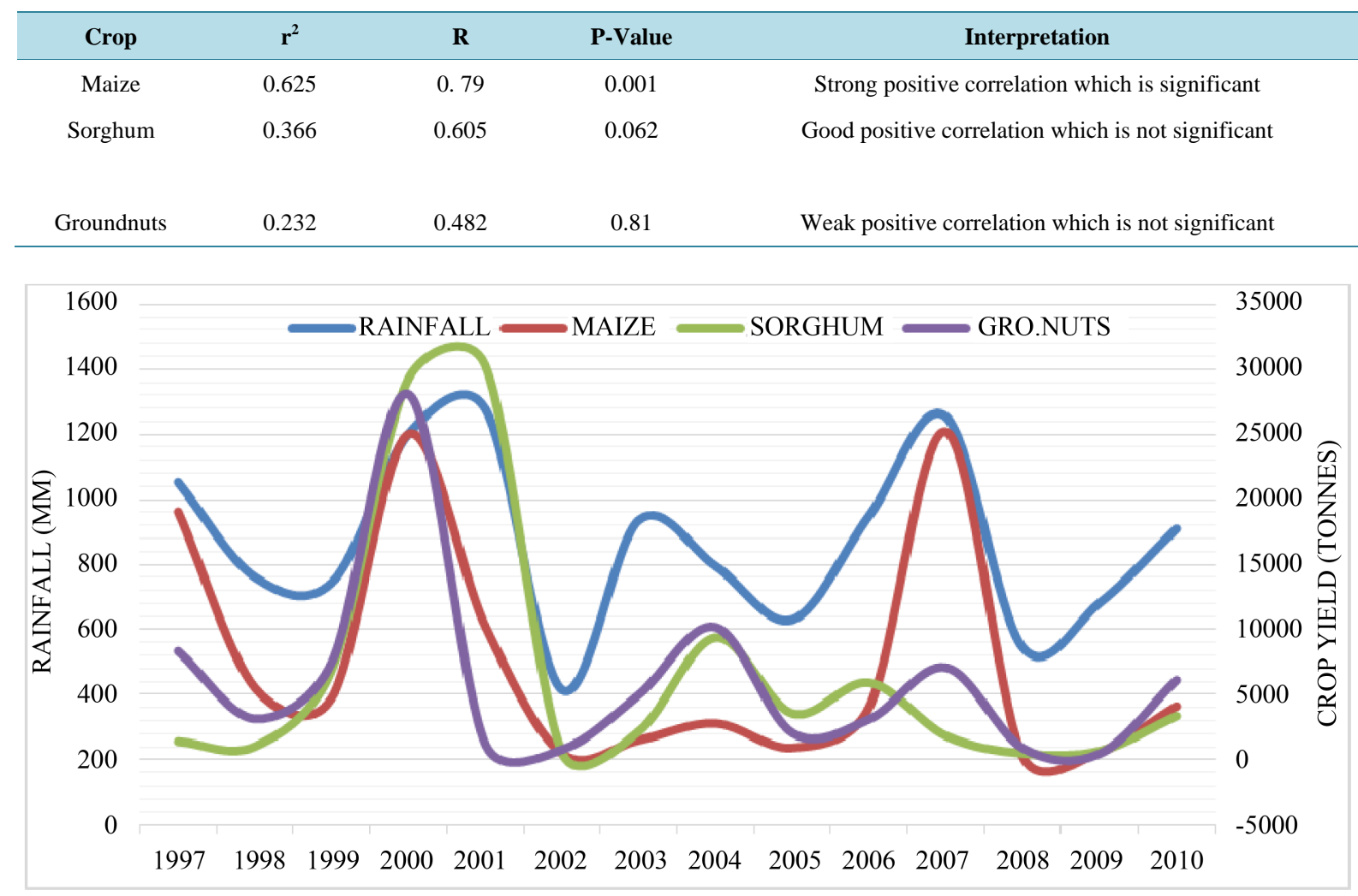

Figure 5. Rainfall and crop yield relationships.

changes field water levels and storage [19]. The water-holding capacity of the atmosphere also increases with higher temperatures; hence even more water will be lost through evaporation [20] hence crops like maize shown to be sensitive to water availability have a high risk of failure in such conditions like those noted in Buhera.

Crops grown in the study area have shown different sensitivity and resilience high variability of precipitation received but generally yields dwindle when the amount of precipitation declines. This different sensitivity could be the key to long term climate resilient agriculture. Maize which is farmed in about $70 \%$ of the arable land in Buhera has been shown to have a significant correlation with the amount of rainfall received hence it must be avoided in the area or planted only in small pockets where local conditions are suitable. This has also been noted by [21]-[23], who state that with a decline in rainfall and increase in temperatures, maize yields in semi-arid areas of Zimbabwe are declining and small grains are the way forward for the farmers.

Sorghum is shown to yield better than maize in conditions of less rain and is less sensitive to rainfall fluctuations hence must be recommended to farmers in years of less rain. Groundnuts are however shown to be the least sensitive to declining rainfall amounts given their weak and insignificant correlation coefficient with rainfall. This means that they are the best in terms of resilient to climatic variability and change. Groundnuts harvests are guaranteed even when rainfall amounts are low. Research done by [24] [25] also concluded that sorghum and groundnuts are drought resistant since they can withstand long dry spells. 


\section{Conclusion}

Using statistical approach the research highlighted the importance of understanding crop sensitivity to climatic variability and change as an important step towards assessment of climate change impact on food security in Zimbabwe. The research also shows that different crops respond differently to the effects of climatic change and variability. Based on the three staple crops tested in the research groundnuts are the least sensitive to climatic variations followed by sorghum; hence their production must be encouraged to local subsistence farmers. The paper also shows that the rate of crop failure in Buhera is high because most farmers concentrate on planting maize which is very sensitive to climatic variations. Planting of maize must be limited to places and local micro-climatic conditions are favourable.

\section{References}

[1] Changnon, S.A. (1998) Commends on Secular Trends of Precipitation Amount, Frequency and Intensity in the United States by Karl and Knight. Bulletin of the American Meteorological Society, 79, 2550-2552.

[2] Hellmuth, M.E., Moorhead, A., Thomson, M.C. and Williams, J. (2007) Climate Risk Management in Africa: Learning from Practice. International Research Institute for Climate and Society, Columbia University, New York.

[3] Slater, A.G. (2007) Chapter 8, Climate Models and Their Evaluation. In: Solomon, S., et al., Eds., Climate Change 2007: The Physical Science Basis. Contribution of Working Group I to the Fourth Assessment Report of the Intergovernmental Panel on Climate Change, Cambridge University Press, Cambridge, 589-662.

[4] Unganai, L. (2009) Adaptation to Climate Change among Agropastoral Systems: Case for Zimbabwe. Earth and Environmental Science, 6, Article ID: 412045. http://dx.doi.org/10.1088/1755-1307/6/41/412045

[5] Schneider, S. and Sarukhan, J (2009) Overview of Impacts, Adaptation, and Vulnerability to Climate Change. In: Mccarthy, J.J., Canziani, O.F., Leary, N.A., Dokken, D.J. and White, K.S., Eds., Climate Change 2001: Impacts, Adaptation, and Vulnerability, Cambridge University Press, Cambridge, 1-17.

[6] Chagutah, T. (2010) Climate Change Vulnerability and Preparedness in Southern Africa: Zimbabwe Country Report. Heinrich Boell Stiftung, Cape Town.

[7] Zimbabwe National Statistics Agency (2012) Census 2012 Preliminary Report. http://unstats.un.org/unsd/demographic/sources/census/2010_phc/Zimbabwe/ZWE_CensusPreliminary2012.pdf

[8] Auret, D. (1990) A Decade of Development Zimbabwe 1980-1990. Mambo Press, Gweru.

[9] Mashingaidze, K. and Mataruka, D.F. (1992) Maize. In: Whingwiri, E.E., Mashingaidze, K. and Rukuni, M., Eds., Small-Scale Agriculture in Zimbabwe: Field Crop Production, Rockwood Publishers, Harare, 45-68.

[10] Rukuni, M. (2006) The Evolution of Agricultural Policy 1890-1990. In: Rukuni, M., Tawonezvi, P., Eicher, C., Munyuki-Hungwe, M. and Matondi, P., Eds., Zimbabwe's Agricultural Revolution Revisited, University of Zimbabwe Publications, Harare, 29-61.

[11] Hamed, K.H. and Rao, A.R. (1998) A Modified Mann-Kendall Trend Test for Autocorrelated Data. Journal of Hydrology, 204, 182-196. http://dx.doi.org/10.1016/S0022-1694(97)00125-X

[12] Von Storch, H. (1995) Misuses of Statistical Analysis in Climate Research. In: Analysis of Climate Variability: Applications of Statistical Techniques, Springer-Verlag, Berlin, 11-26. http://dx.doi.org/10.1007/978-3-662-03167-4_2

[13] Dietz, E.J. and Killeen, T.J. (1981) A Nonparametric Multivariate Test for Monotone Trend with Pharmaceutical Applications. Journal of the American Statistical Association, 76, 169-174.

[14] Hirsch, R.M. and Slack, J.R. (1984) A Nonparametric Trend Test for Seasonal Data with Serial Dependence. Water Resources Research, 20, 727-732. http://dx.doi.org/10.1029/WR020i006p00727

[15] Washington, R., Harrison, M. and Conway, D. (2004) African Climate Report. Report Commissioned by the UK Government to Review African Climate Science, Policy and Options for Actions. UK Department for Environment Food and Rural Affairs and the Department for International Development, London, UK, 45 p.

[16] Weber, E.U. (2010) What Shapes Perceptions of Climate Change? Wiley Interdisciplinary Reviews: Climate Change, 1, 332-342. http://dx.doi.org/10.1002/wcc.41

[17] Simba, F.M., Chikodzi, D. and Murwendo, T. (2012) Climate Change Scenarios, Perceptions and Crop Production: A Case study of Semi-Arid Masvingo Province in Zimbabwe. Journal of Earth Science \& Climatic Change, 3, 124.

[18] McCarthy, J.J., Canziani, D.F., Leary, N.A., Dokken, D.J. and White, K.S. (2001) Climate Change Impacts, Adaptation and Vulnerability. Cambridge University Press, Cambridge, New York, 1032 p.

[19] Bouwer, L.B. (2007) Estimates of Spatial Variation in Evaporation Using Satellite-Derived Surface Temperature and a Water Balance. Wiley InterScience, New York, 670-682. 
[20] Bates, B.K. (2008) Climate Change and Water. Technical Paper of the Intergovernmental Panel on Climate Change, IPCC Secretariat, Geneva.

[21] Gundry, S., Wright, J.A., Austin, E. and Worrall, E.J. (1999) Populating a Simulation Model of the Food System in Zimbabwe with Representative Household Data. International Congress on Modeling and Simulation Proceedings, University of Waikato, New Zealand, 6-9 December 1999. http://www.mssanz.org.au/MODSIM99/Vol\%202/Gundry.pdf

[22] FAO (2006) Fertilizer Use by Crop in Zimbabwe. FAO, Rome.

[23] Vogel, S. and O’Brian, S. (2006) Paying for Environmental Services. World Bank, 2, 255-272.

[24] Aiken, W.H. (2000) On Evaluating Agricultural Research. In: New Directions for Agricultural Research: Neglected Dimensions and Emerging Alternatives, Roman and Allanheld, Totowa.

[25] Abbs, D.J. (1999) A Numerical Modeling Study to Investigate the Assumptions Used in the Calculation of Probable Maximum Precipitation. Water Resources Research, 35, 785-789. http://dx.doi.org/10.1029/1998WR900013 